\title{
Factors Associated With Nurses' Negative Behaviour at a Public Health Facility in Namibia
}

\author{
Nestor Tomas ${ }^{1}$, Kefiloe A. Maboe ${ }^{1} \&$ Marang T. Mamahlodi ${ }^{1}$ \\ ${ }^{1}$ Department of Health Studies, University of South Africa, Unisa, South Africa \\ ${ }^{2}$ Department of General Nursing, University of Namibia (UNAM), Rundu Campus, Namibia \\ Correspondence: Professor Kefiloe A. Maboe, Department of Health Studies, University of South Africa, PO Box \\ 392, Unisa 0003, South Africa. Tel: 27-(0)12-429-2393. E-mail: maboeka@unisa.ac.za
}

Received: July 11, 2019 Accepted: September 9, 2019 Online Published: November 20, 2019

doi:10.5539/gjhs.v11n13p112 URL: https://doi.org/10.5539/gjhs.v11n13p112

\begin{abstract}
Caring behaviour is central to all health care organizations and their employees. Nurses spend considerable time with patients and they are ethically bound to provide quality nursing care, regardless of their patients' social class, gender or ethnic background. To improve patients' experience of care, it is important that nurses are aware of factors - both within themselves and in their working environment - that might influence their attitude and behaviour. The purpose of this study was to describe and assess factors contributing to nurses' negative behaviour at a public health facility in Namibia. A quantitative, non-experimental, explorative and descriptive design was used. Simple random sampling was used to select 64 nurses. A pre-tested questionnaire was used to collect data, which were then analysed with the Statistical Package for the Social Sciences (SPSS), version 23, using descriptive statistics.

The study results showed a strong association of nurses' negative behaviour to management's reluctance to address the nurses' negative behaviour, $85.9 \%$ (55) and patients' behaviour and cultural practices $73.4 \%$ (47). The study recommended that rewarding nurses who display acceptable behaviour would be one of the cost effective strategy to motivate nurses who display professional behaviour.
\end{abstract}

Keywords: public health care facilities, negative behaviour, nurse, nursing, patients

\section{Introduction and Background}

The standards governing the nursing profession in any country are administered by a national regulatory body that controls the practices of all registered persons. Salmani, Hasanvad and Mandegari (2017) reaffirmed that every nurse has an ethical responsibility to behave professionally and in accordance with public expectations. Quality patient-centred care requires motivated, competent personnel and a good working climate that supports and addresses the concerns of the staff (Almost, Wolff, Mildon, Price, Godfrey, Robinson, Ross-White, \& Mercado-Mallari, 2015). A healthy working environment helps to foster a climate where nurses feel challenged to use their expertise to achieve their personal goals and those of the organization. Kieft, de Brouwer, Francke \& Delnoij (2014) identified clinical competency, adequate staffing, nurse manager support, control over nursing practice and patients' cultural values to be among some of the essential factors influencing nurses' behaviour. Namibia, like many developing countries, is faced with challenges related to the provision of quality nursing care. The Namibian Nursing Council (2016) indicated that between 2014 and 2015, 25\% of the cases reported to the Nursing Council involved shouting at and scolding patients, showing them a lack of respect and ignoring their needs.

Gimenes and Faleiros (2014) stated that the nursing profession is faced with extensive challenges that have the potential to harm the image of the profession. In Namibia, the provision of quality nursing care is further compromised by the fact that $85 \%$ of the population relies on public health services because of the high unemployment rate and the exorbitant fees charged by private health facilities. Furthermore, the emergence of communicable and non-communicable diseases and a notable population increase of 15\% from 2001 to 2011 has added to the pressures on public/government nurses to meet the public's demands (Namibia Statistics Agency, 2011). According to Trading Economics (2017) the 2012 Presidential Commission of Inquiry launched into the state of Namibia's public health sector found that the shortage of nurses was a major contributing factor to nurses' 
negative behaviour. As a result, the Ministry of Health and Social Services (MoHSS) introduced a three-and-a-half-year ( $\left.3 \frac{1}{2}\right)$ diploma course in nursing and midwifery science and signed several memorandums of understanding (MoUs) with neighboring countries, namely Zimbabwe and Kenya, to import about a thousand nurses a year (Trading Economics 2017:2). In addition, two new local universities, namely International University of Management (IUM) and Welwitchia University (WU), introduced new courses in nursing in 2014 in order to address the shortage of nurses (MoHSS, 2014). In addition, a six-month health extension programme was introduced for health extension workers to ease the burden on nurses (MoHSS, 2014). As a result, UNAM (2013) graduation statistics showed that the number of graduates increased from 532 to 680 between 2012 and 2013 . Additionally, 460 nurses graduated from the five MoHSS training centres and about $85 \%$ of graduates were absorbed into the public health care facilities (MoHSS, 2013). Nevertheless, despite these efforts to address the shortage of nurses, public resentment criticism has continued to be expressed on various media platforms (The Namibian news article, 2018).

\subsection{Problem Statement}

The Ministry of Health and Social Services has pledged its total commitment to the provision of quality public health care services in in all the Namibian public health care facilities (MoHSS, 2014). However, the provision of health services at most public health care facilities is contrary to the MoHSS goal providing quality health care. Poor staff attitudes have been reported; nurses have been reported being rude, impatient, and incompetent and displaying neglecting behaviour toward the patients (The Namibian newspaper, 2015; MoHSS, 2013). The public outcry regarding the negative nurses' behaviour at most public health facilities continues to surface in media reports; newspapers, radio talk shows and Health Professional Council report (The Namibian Sun newspaper, 2015).

Previous studies done in Namibia mainly focused on factors influencing the performance of nurses and little was done to investigate the factors associated with negative nurses' behaviour. Quality nursing care will continue to be compromised if the current phenomena is not investigated and addressed. This study central question was "what are the factors responsible for negative nurses' behaviour at the specific public health facility? This study emerged to assess public dissatisfaction observed by the researcher who is a nurse and the dissatisfaction expressed through the media and further to respond to the Presidential Commission of inquiry recommendations on the quality of public care, conducts and ethics and attitudes vis-à-vis patients. The study was significant to inform the health facility on factors hindering the provision of quality care and made recommendations for future research needed to develop strategies that promote patient-centred care.

\subsection{Objectives of the Study}

The objective of the study was to assess and describe factors contributing to nurses' negative behaviour in the selected public health care facility.

\section{Methodology}

\subsection{Study Design and Setting}

This study was conducted in an urban hospital in Namibia serving as a referral hospital for the three regions being Kavango East region, Kavango West region and Zambezi region.

A non-experimental, explorative, descriptive and quantitative design was used. The purpose of this study was to explore and describe factors contributing to the nurses' negative behaviour in rendering care to patients in this specific public health.

\subsection{Population and Sample Size Determination}

The population of 200 at the specific health facility comprised two categories of nurses namely 77 registered nurses and 123 enrolled nurses. The two categories of nurses comprised of nurses with certificates up to degree level and were the only categories of nurses at the specific health care facility. According to De Vos, Strydom, Fouché and Delport (2011) sampling size guidelines, $32 \%$ of respondents from each of the two categories of nurses, that is, 25 registered nurses and 39 enrolled nurses was drawn. The total sample size of 64 nurses was adequate and acceptable according to De Vos et al. (2011) guidelines. However, the sample size could not be properly determined based on the fact that the variance in a study sample could not be inferred to the population sample.

\subsection{Sampling Technique and Study Period}

A stratified random sampling technique was used to draw a study population from two different segments or categories of nurses, according to the number of persons in that stratum (Burns \& Grove, 2011). The strata comprised of different categories of nurses (registered nurses and enrolled nurses) in a specific health care facility. 
From each stratum the number of respondents to be selected used simple random sampling to ensure that all respondents had equal chance to be selected for the study. In each stratum, the researcher used simple random sampling to select the number of respondents, thus ensuring that all respondents had an equal chance of being selected for the study. The study was conducted from February 2016 to June 2017.

\subsection{Inclusion and Exclusion Criteria}

All nursing the two categories found at the specific public health care facility, being the registered nurses and enrolled nurses who were willing to participate were included in the study. The study excluded nurses who were not willing to take part and those not in employment at the selected health care facility and those working for the private sector.

\subsection{Data Collection Tool}

A structured questionnaire was used to collect demographic characteristics and factors associated with nurses' negative behaviour. The questionnaires were formulated in English and consisted of six sections, with a total of 13 closed-ended questions and five open-ended questions. The demographic information was collected using dichotomous questions, while factors associated with nurses' negative behaviour were collected using Likert scale questions and open-ended questions. The entire questionnaire took about 20 to 30 minutes to complete. Section A examined the demographic information, including gender, level of education, rank and age. Section B examined staffing and work schedules, which included aspects related to the nurse-patient ratio. Section C covered aspects related to remuneration, including salaries, recognition and rewards. Section D covered aspects related to leadership and management styles, section E examined the nurses' working environment and section F covered aspects related to patient behaviour and patients' cultural practices.

\subsection{Data Collection and Analysis}

Data were collected using a pre-tested self-administered structured questionnaire. Data management and analysis were undertaken using the Statistical Package for the Social Sciences (SPSS), version 23. Descriptive statistics were summarised and presented as percentages. Open-ended questions were analysed manually, using thematic coding. Common responses were grouped together using short codes. An independent coder was used to confirm the findings, while a literature control was conducted in order to support the formulated themes. Binary logistic regression, with a $95 \%$ confidence interval, was used to identify the factors independently associated with the nurses' negative behaviour. Statistical significance was accepted at the 0.05 level.

Headings were assigned an " $n$ " value to indicate the number of respondents that participated in the study.

\subsection{Validity and Reliability}

Data collection instrument was pre-tested before it was utilized for the main study to determine the accuracy and consistency of the research instrument. The questionnaire used was validated by the statistician and approved by the supervisor. Furthermore, the study was conducted in a language understood both by respondents and the researcher while the same questionnaire was administered to all respondents during data collection.

\subsection{Ethical Consideration}

The procedure for this study was presented to the University of South Africa's (Unisa's) Research and Ethics Committee, in the Department of Health Studies and to the Ministry of Health and Social Services, whereupon written approval was granted. The researcher ensured that the study adhered to the Helsinki Declaration by obtaining voluntary written informed consent from the participants, after explaining the study purpose and objectives. The respondents were also informed of their right to withdraw from the study at any time, without incurring any penalties.

\section{Results}

There was a total of 64 respondents in this study and a $100 \%$ response rate.

\subsection{Biographical Data $(N=64)$}

All respondents $100 \%$ (64) were nurses working at the specific health care facility. Respondents were divided into two categories, namely enrolled nurses $61 \%$ (39) and registered nurses $39 \%$ (25). Concerning gender, $44 \%$ (28) respondents were male and $56 \%$ (36) were female. This was confirmed by the literature, which indicated that $97 \%$ of the nursing workforce in Namibia was made up of females (WHO, 2014). Respondents' ages were categorised as $20-29$ years $44 \%$ (28). 30-39 years $34 \%$ (22) and $40-49$ years $22 \%$ (14). 
Table 1. Distribution of respondents by socio-demographic characteristics

\begin{tabular}{lcc}
\hline & Frequency (n) & Percentage (\%) \\
\hline Rank & 25 & 39 \\
Registered nurses (R/N) & 39 & 61 \\
Enrolled nurses (E/N) & 28 & \\
\hline Gender & 36 & 44 \\
Male & & 56 \\
Female & 28 & \\
\hline Age category & 22 & 44 \\
$20-29$ years & 14 & 34 \\
$30-39$ years & 0 & 22 \\
$40-49$ years & & 0 \\
$>50$ & 17 & 26 \\
\hline Education & 39 & 60 \\
Diploma & 5 & 8 \\
Certificate & 3 & 5 \\
Degree & 0 & 0 \\
Postgraduate & & $\mathbf{1 0 0}$ \\
Masters/PHD & 30 & 47 \\
\hline Years of experience & 20 & 31.3 \\
$0-5$ years & 8 & 12.5 \\
6-10 years & $6 \mathbf{4}$ & \\
$11-15$ years & & \\
$>16$ years & & \\
Total & & \\
\hline
\end{tabular}

\section{Factors associated with negative behaviour}

This section presents the results of the associated factors to negative behaviours factors associated with negative behaviour.

\subsection{Staffing and Work Schedule $(N=64)$}

More than half $54.7 \%$ (35) of the respondents strongly disagreed that sufficient staff were allocated for the unit's workload, whereas $13(20.3 \%)$ disagreed. With regard to staff input, $28(43.8 \%)$ disagreed and $11(17.2 \%)$ strongly disagreed that staff input on staffing issues was considered by management. Almost half $(28 ; 43.8 \%)$ of the respondents agreed that their departments were staffed with nurses with the appropriate skills, whereas $21(32.8 \%)$ strongly agreed. In response to the question about whether a flexible work schedule exists in the unit, more than half $(33 ; 51.6 \%)$ of the respondents agreed, while $17(26.6 \%)$ strongly agreed.

The responses to the open-ended questions indicated that an appropriate nurse-patient ratio was not implemented $(48 ; 75 \%)$. These responses were confirmed by the literature, which indicated that a shortage of nurses and poor working conditions caused many nurses to leave public health care facilities, thereby compounding the pressure already experienced by overburdened staff and causing them to develop work-related stress and frustrations (MoHSS, 2014). Some of the common suggestions by the respondents indicated that there was a need to hire more staff members and more students needed to be enrolled in nursing courses. This was confirmed by the Amakali (2013) who indicated that staff norms need to be in place in order to determine the workload and the number of staff to be allocated to each health care facility. The study showed that respondents were dissatisfied with the allocation of staff members in the unit and the lack of acknowledgement of staff input on staffing issues by the management of the specific health care facility. 


\subsection{Remuneration, Rewards, Benefits and Recognition $(N=64)$}

The majority of respondents $(21 ; 32.8 \%)$ disagreed and 19 (29.7\%) strongly disagreed that remuneration was market-related. In response to whether remuneration is based on years of experience and responsibility, 27 (42.2\%) disagreed, while $23(35.9 \%)$ strongly disagreed. With regard to awards rewards, half (32; 50\%) strongly disagreed and $28(43.8 \%)$ disagreed that the organisation gives recognition to hard-working nurses or top performers in the form of awards rewards. In addition, $20(31.3 \%)$ of the respondents strongly disagreed that there were opportunities for professional growth, while 17 (26.6\%) disagreed. Furthermore, 24 (37.5\%) of the respondents strongly disagreed that incentives for retaining staff were available, while $20(31.3 \%)$ disagreed. Almost half ( 31 ; $48.4 \%$ ) of the respondents strongly disagreed that nurses identified as displaying negative behaviour were supported and retrained, while $24(37.5 \%)$ disagreed with the statement. This could imply that nurses displaying negative behaviour were not identified to attend relevant courses or be retrained, which may continue to affect the delivery of quality nursing care. It was evident that respondents were not aware of the availability or the implementation of performance appraisal, as $22(34.4 \%)$ strongly disagreed and $30(46.9 \%)$ disagreed that performance appraisal was available and was being implemented. With regard to the reasons for conducting performance appraisal, the majority $(23 ; 35.9 \%)$ strongly disagreed and $15(23.4 \%)$ disagreed that they knew the reasons for performance appraisal; 12 respondents $(18.8 \%)$ were uncertain whether the reasons for performance appraisal were known by staff members.

Some respondents agreed on certain aspects of reward and recognition, as the majority $(30 ; 46.8 \%)$ agreed that nurses were provided with opportunities to attend relevant courses, whereas $24(37.5 \%)$ strongly agreed. On the other hand, $28(43.8 \%)$ strongly agreed that in-service training provides the needed support, while $2(3.1 \%)$ strongly disagreed. The above responses were confirmed by the responses to the open-ended questions, with 61 (95.3\%) of the respondents indicating that no special incentives for the Intensive Care Unit (ICU) and theatre had been introduced, while $49(76.6 \%)$ suggested that management must start rewarding and recognising hard-working nurses so that they would feel motivated.

Booyens and Bezuidenhout (2014) have indicated that improved salary benefits, incentives and other conditions of service were among other strategies to improve performance and retain health professionals. In contrast, Hendra \& Rezki (2015) claimed that employees' performance was primarily driven by intrinsic motivation, (rather than by extrinsic motivation (e.g. wages or salaries).

\subsection{Leadership and Management Styles $(N=64)$}

The majority $(29 ; 45.3 \%)$ of the respondents agreed and $23(35.9 \%)$ strongly agreed that their supervisor motivates them to perform at their best with regard to items related to their job descriptions; 34 (53.1\%) respondents agreed and $14(21.9 \%)$ strongly agreed that copies of the job descriptions were available to employees. Moreover, 24 (37.5\%) respondents agreed that their managers welcome new ideas and suggestions, while $18(28.1 \%)$ strongly agreed with this statement. In addition, half $(32 ; 50 \%)$ of the respondents agreed and $13(20.3 \%)$ strongly agreed that the mission and vision of the organisation were known to the employees. The majority $(30 ; 46.9 \%)$ indicated that they strongly agreed about working towards achieving the organisation's mission and vision, whereas 12 $(18.7 \%)$ agreed. Furthermore, $26(40.6 \%)$ agreed that induction and orientation programmes were provided for all new employees, while 24 (37.5\%) strongly agreed. In response to the question about role modelling, most of the respondents $(20 ; 31.3 \%)$ agreed and $10(15.6 \%)$ strongly agreed that their supervisor was a role model. This was supported by Karkada \& Cherian (2017) whose study revealed that leaders that act as a driving force in the organisation are considered inspirational leaders.

A quarter $(16 ; 25 \%)$ of the respondents strongly disagreed and $30(46.9 \%)$ disagreed that the supervisor gives immediate feedback concerning performance. With regard to the involvement of staff in planning and decision-making, $11(17.2 \%)$ strongly disagreed and more than half $(33 ; 51.6 \%)$ disagreed that the organisation promotes staff involvement in planning and decision-making. In response to the question regarding public involvement in planning, $28(43.8 \%)$ disagreed that management involves members of the public in the achievement of organisational goals.

Respondents suggested that in order to improve aspects related to leadership and management, the supervisor should give immediate feedback and the public should be involved in planning and decision-making. It can be deduced from the respondents' responses that there are certain aspects that need the attention of management to reduce the negative feelings and behaviour of the nurses. This was supported by the literature, which indicated that public participation is crucial for organisational success and that supervisors need to be empowered to provide effective supervision (Amakali, 2013). 


\subsection{Working Environment $(N=64)$}

The majority $(30 ; 46.9 \%)$ of the respondents agreed with the statement that nurses spend more time on paperwork/administrative duties and therefore have less time for their patients; 24 (37.5\%) respondents strongly agreed with this statement. This implies that the provision of quality nursing care may be compromised. In response to the question regarding equipment and materials, more than half $(38 ; 59.4 \%)$ agreed and $18(28.1 \%)$ strongly agreed that the needed equipment and materials were available in the unit. It was clear from the responses that safety in the workplace was guaranteed: $24(38.1 \%)$ agreed and 19 (30.2\%) strongly agreed with this statement.

\subsection{Patients' Behaviour and Cultural Beliefs $(N=64)$}

More than half (46; 73\%) of the respondents either agreed (20;31.2\%) or strongly agreed (27: $42.2 \%)$ that some cultural beliefs of patients were in conflict with the vision of the organisation. This indicates that local cultural practices around the specific health care facility will continue to affect the provision of quality nursing care if no suitable interventions are forthcoming. In response to the question regarding the role of nurses, $20(31.3 \%)$ respondents agreed that patients appreciate the role played by nurses and $21(32.8 \%)$ strongly agreed.

\section{Discussion of Research Results}

Of the 64 respondents who participated in this study, the majority were enrolled nurses $(39 ; 61 \%)$. The smaller number of registered nurses $(25 ; 39 \%)$ in the study suggested that the enrolled nurses at the health care facility were working with minimal supervision. The reviewed literature stated that the scope of the enrolled nurses should be part of the nursing regime that is planned and initiated by the registered nurse and carried out under his or her direct supervision (Republic of Namibia, 2014). This presents a challenge, given the shortage of staff at the health care facility.

The majority (28; 44\%) of respondents were in their early to mid-twenties (20-29 years) and had less than five (5) years of working experience. The greater number of young nurses in the profession was attributed to the call for more nurses in the country by the Minister of Health and Social Services (Nembwaya, 2013). This finding was contrary to the study findings on young peoples' perceptions of the nursing profession, which revealed that young people did not value a career in nursing and viewed it as an inferior profession in society (Glerean, Hupli, Talman \& Haavisto, 2017). From the responses given, it may be concluded that the more experienced nurses are leaving the health profession, which makes it difficult for young nurses to be properly supervised during their first few years in the profession. The respondents held various nursing qualifications, but the majority $(39 ; 60 \%)$ were in possession of a certificate in nursing. These results were supported by a study on the barriers to professional development among nurses in Saudi Arabia, which showed that $29.7 \%$ of the respondents could not further their studies because of their heavy working schedules, while $38.2 \%$ had no financial means to further their studies (Al-Bashaireh, 2012).This has a negative effect on the quality of nursing care and the attitude and behaviour required to execute the nursing interventions.

It was evident that staff shortages was a problem for many of the respondents, as the majority $(35 ; 54.7 \%)$ indicated that insufficient staff were allocated to their unit to handle the workload. One of the factors believed associated with increased workload was the lack of acknowledgement of staff input on aspects related to staffing issues. The results of the study were supported by the study conducted by Amakali (2013), which indicated that shortage of staff can compromise the delivery of quality nursing care. As indicated by Booyens and Bezuidenhout (2014), remuneration, rewards, benefits and recognitions were referred to as "hygienic factors". These factors include satisfactory salaries, job promotions and job security; if these factors are applied, individuals will have job satisfaction, display positive behaviour and increase their productivity.

The majority of the respondents were dissatisfied with their current salary, as 21 (32.8\%) of them disagreed that their remuneration was market- related, in comparison with only $5(7.8 \%)$ who strongly agreed that their remuneration was market-related. The assumption can be made that many experienced nurses have left the specific public health care facility owing to frustrations related to their remuneration. These results were disputed by Hendra and Rezki (2015) who stated that employees' performance depended primarily on intrinsic motivation rather than on extrinsic motivation (e.g. wages or salaries).

The majority of respondents $(31 ; 48.4 \%)$ agreed that nurses identified as displaying negative behaviour were neither supported nor retrained. Only $1(2 \%)$ respondent indicated that steps were taken to support and retrain nurses identified with negative behaviour. This is a matter of concern in terms of the provision of quality nursing care, since the absence of hygienic factors are associated with negative behaviour.

Leadership and management play an important role in promoting a good working environment and maintaining the 
needed behaviour to achieve organisational goals. The findings highlight the supervisors' need to give immediate feedback to their subordinates, as the majority $(30 ; 46.9 \%)$ of the respondents indicated that their supervisors do not give immediate feedback, while others $(33 ; 51.6 \%)$ felt that the organisation does not promote staff involvement in planning and decision-making. Reeves, West and Barron (2013) has shown that prompt feedback creates an awareness among nurses to take ownership of the planning and implementation of nursing interventions. Moreover, the majority $(28 ; 43.8 \%)$ felt that it was a matter of concern that management does not involve members of the public in attempting to achieve the organisational goals.

It may be assumed that the lack of immediate feedback by supervisors and the lack of public and staff involvement in planning and decision-making, implied that critical issues affecting both the nurses and the public are overlooked. Providing sufficient feedback to the employees is one of the important measures to improve productivity. Immediate feedback influences the behaviour of nurses, as it helps individuals to set specific and measurable targets for improvement and to describe methods for attaining those (Booyens \& Bezuidenhout, 2014). The working environment can positively or negatively influence staff behaviour. Almost half $(30 ; 46.9 \%)$ of the respondents were dissatisfied with the fact that nurses spend more time attending to paperwork than they do in caring for their patients. The increase in administrative tasks has been shown to be associated with increasing time pressure and low job satisfaction, leading to a compromised quality of nursing care and work-related stress and negative behaviour among nurses (Wilson, 2017).

Nevertheless, it was encouraging to hear - according to the majority of respondents $(38 ; 59.4 \%)$ that the needed equipment was available in the unit and that safety in the workplace was guaranteed. The latter finding was supported by the majority $24(38.1 \%)$ of respondents, who agreed that they feel safe in their working environment. It was noted that certain aspects of patients' behaviour and cultural beliefs compromise the quality of nursing care; the majority $(27 ; 42.2 \%)$ strongly agreed with this statement and $20(31.2 \%)$ agreed that some cultural beliefs were in conflict with the provision of quality nursing care. The assumption was that the specific health care facility serves people of diverse cultures, who have different norms and values. Therefore, some families with strong beliefs in traditional healers were associated with difficulties to comply with health advice and lack of respect for the nurses; consequently, leading to nurses developing negative attitudes and behaviour towards those who disregard their advice. Nevertheless, it was encouraging to note that 21 respondents (32.8\%) strongly agreed and $20(31.3 \%)$ agreed that patients appreciate the role played by the nurses. The nurses believed that their patients understand the important role they play in society. Sadly, however, the various factors contributing to nurses' negative behaviour have negative implications for patient care and have damaged the reputation of the nursing profession.

\subsection{Recommendations}

The study recommends that funds be obtained to improve the training of nurses and the recruitment process as a strategy to address the shortage of nurses. Moreover, nurses identified with negative behaviour should be retrained and supported with a view to behavioural change and customer-oriented services. Nurses should also be remunerated adequately and rewarded and recognized for their hard work, as this could motivate them to perform better. Finally, the study researcher recommends increasing nurses' patient contact and minimizing their paperwork/administrative tasks.

\subsection{Study Delimitations and Limitations}

The study was delimited to factors associated with negative nurses' behaviour employed by the specific public health care facility. Furthermore, the study sample size of 64 respondents was a limitation since the variance in study sample could not be inferred to the population, that is, each nursing school has its own criteria of choosing students and this criteria is not uniform to all nursing schools in the country.

\section{Conclusion}

The study established that nurses' negative behaviour in the specific health care facility was associated with various factors being the shortage of staff and work overload, lack of suitable interventions and training to deal with identified negative behaviour. Other factors associated with negative behaviour were poor remuneration, the poor leadership style of management, the unsatisfactory working environment and patients' behaviour and cultural beliefs. These factors will continue to exacerbate nurses' negative behaviour if they are not addressed urgently and effectively.

\section{Acknowledgements}

The researcher would like to thank Unisa's masters and doctoral bursary programme for their financial assistance in completing this study. 


\section{Funding}

This study was funded by Unisa Master's and doctoral Bursary programme.

\section{Competing Interests Statement}

No potential conflict of interest was reported by the authors.

\section{References}

Al-Bashaireh, A., (2012). Barriers for Continuing Professional Development among Nurses in a Saudi Arabia. Middleeast journal of nursing, 6(3), 22-27.

Almost, J., Wolff, A., Mildon, B., Price, S., Godfrey, C., Robinson, S., Ross-White, A., \& Mercado-Mallari, S. (2015). Positive and negative behaviours in workplace relationships: a scoping review protocol. BMJ open, 5(2), 1-6. https://doi.org/10.1136/bmjopen-2015-007685

Amakali, L. (2013). Human resources capacity in the Ministry of Health and Social Services in Namibia. Magister Technologiae. UNISA.

Booyens, S., \& Bezuidenhout, M. (2014). Dimensions of Healthcare Management (3rd ed.).Cape Town: Juta.

Gimenes, F. R. E., \& Faleiros, F. (2014). Nursing challenges for the 21 st century. Journal of nursing \& care, $3(143), 1-3$.

Glerean, N., Hupli, M., Talman, K., \& Haavisto, E. (2017).Young peoples' perceptions of the nursing profession: An integrative review. Nurse Education Today, 57(2017), 95-102. https://doi.org/10.1016/j.nedt.2017.07.008

Hendra, G., \&, Rezki, A. (2015). Wages and Employees Performance: The Quality of Work Life as Moderator. International Journal of Economics and Financial Issues, 5(Special issue), 349-353.

Cherian, S., \& Karkada, S. (2017). A Review on Leadership in Nursing. International journal of nursing research and practice, 4(1), 1-10. https://org/10.15509/IJNRP.2017.4.1.347

Kieft, R. A., de Brouwer, B. B., Francke, A. L., \& Delnoij, D. M. (2014). How nurses and their work environment affect patient experiences of the quality of care: a qualitative study. BMC health services research, 14, and 249. https://doi.10.1186/1472-6963-14-249

Nembwaya, H., (2013). Nam faces shortage of nurses. The Namibian. Retrieved 10 August, 2017, from http://www.namibian.com.na

The Namibian Sun newspaper. (2015). Attitude transplant needed at health. Retrieved 27 August, 2017, from https://www.namibiansun.com/news/attitude-transplant-needed-at-health3/

Nursing Council. (2016). Statistics report. Windhoek.

Reeves, R, West, E., \& Barron, D. (2013). Facilitated patient experience feedback can improve nursing care: a pilot study for a phase III cluster randomised controlled trial. BMC Health Services Research, 13, 259. https://doi.org/10.1186/1472-6963-13-259

Republic of Namibia. (2013). Commission of Enquiry, Windhoek, MoHSS.

Republic of Namibia. (2014). Nursing Act No 8 of 2014. Windhoek: Government Printer.

Salmani, N., Hasanvand, S., Bagheri, I., \& Mandegari, Z. (2017). Nursing Care Behaviours Perceived by Parents of Hospitalized Children: A Qualitative Article. Int J Pediatr, 5(7), 5379-5389.

The Government of the Republic of Namibia. Ministry of Health and Social Services. (2014). Assessment of the National Quality Management Systems used to monitor and improve quality in health service provision in hospitals and health centres in Namibia. Windhoek: Government Printer.

The Government Republic of Namibia. Namibia Statistics Agency. (2011) .Population and Housing Census. Retrieved 8 August, 2018, from https://nsa.org.na/

The Namibian news article. (2018). February. 2

The Namibian newsarticle. (2012). 15 November: 1.

The Namibian newsarticle. (2015). 09 November: 2.

Trading economics. (2017). Namibia unemployment rate. Retrieved 10 January, 2017, from http://www.tradingeconomics.com/namibia/unemployment-rate

University of Namibia. (2012). Graduation report. Retrieved 29 September, 2017, from 
http://www.unam.edu.na/about-unam/statistics

Vries, K. (2013). Serious indictment of the ministry of health. Windhoek observer. Retrieved 6 January, 2016, from http://www.observer.com.na/national/1242-serious-indictment-of-ministry-of-health

Wilson, B. (2017). Charting Vs Patient Care. New York Times. Nursing link. Retrieved from $\mathrm{http}$ ://nursinglink.monster.com/benefits/articles/21608-charting-vs-patient-care

World Health Organisation. (2014). Analytical summary-health workforce. Retrieved 01 February, 2017, from http://www.aho.afro.who.int/profiles_information/index.php/Namibia:Analytical_summary_-_Health_work force

\section{Copyrights}

Copyright for this article is retained by the author(s), with first publication rights granted to the journal.

This is an open-access article distributed under the terms and conditions of the Creative Commons Attribution license (http://creativecommons.org/licenses/by/4.0/). 